\title{
Air pollution and the development of asthma from birth until young adulthood
}

\author{
Ulrike Gehring ${ }^{1}$, Alet H. Wijga ${ }^{2}$, Gerard H. Koppelman (103,4, Judith M. Vonk (id) ${ }^{4,5}$, \\ Henriette A. Smit ${ }^{6}$ and Bert Brunekreef ${ }^{1,6}$
}

Affiliations: ${ }^{1}$ Institute for Risk Assessment Sciences, Utrecht University, Utrecht, The Netherlands. ${ }^{2}$ Center for Nutrition, Prevention and Health Services, National Institute for Public Health and the Environment, Bilthoven, The Netherlands. ${ }^{3}$ Dept of Pediatric Pulmonology, Beatrix Children's Hospital, University Medical Center Groningen, University of Groningen, Groningen, The Netherlands. ${ }^{4}$ Groningen Research Institute for Asthma and COPD, University of Groningen, Groningen, The Netherlands. ${ }^{5}$ Dept of Epidemiology, University Medical Center Groningen, University of Groningen, The Netherlands. ${ }^{6} J u l i u s$ Center for Health Sciences and Primary Care, University Medical Center Utrecht, Utrecht, The Netherlands.

Correspondence: Ulrike Gehring, Institute for Risk Assessment Sciences, Utrecht University, P.0. Box 80178, 3508 TD Utrecht, The Netherlands. E-mail: u.gehring民uu.nl

@ERSpublications

Early-life exposure to air pollution, especially from motorised traffic, may have long-term consequences for asthma development, as it is associated with an increased risk of developing asthma through childhood and adolescence into early adulthood https://bit.ly/39uZHVH

Cite this article as: Gehring U, Wijga AH, Koppelman GH, et al. Air pollution and the development of asthma from birth until young adulthood. Eur Respir J 2020; 56: 2000147 [https://doi.org/10.1183/ 13993003.00147-2020].

\section{ABSTRACT}

Background: Air pollution is associated with asthma development in children and adults, but the impact on asthma development during the transition from adolescence to adulthood is unclear. Adult studies lack historical exposures and consequently cannot assess the relevance of exposure during different periods of life. We assessed the relevance of early-life and more recent air pollution exposure for asthma development from birth until early adulthood.

Methods: We used data of 3687 participants of the prospective Dutch PIAMA (Prevention and Incidence of Asthma and Mite Allergy) birth cohort and linked asthma incidence until age 20 years to estimated concentrations of nitrogen dioxide $\left(\mathrm{NO}_{2}\right)$, particulate matter with a diameter $<2.5 \mu \mathrm{m}\left(\mathrm{PM}_{2.5}\right),<10 \mu \mathrm{m}$ $\left(\mathrm{PM}_{10}\right)$, and $2.5-10 \mu \mathrm{m}$, and $\mathrm{PM}_{2.5}$ absorbance ("soot") at the residential address. We assessed overall and age-specific associations with air pollution exposure with discrete time-hazard models, adjusting for potential confounders.

Results: Overall, we found higher incidence of asthma until the age of 20 years with higher exposure to all pollutants at the birth address (adjusted odds ratio (95\% CI) ranging from 1.09 (1.01-1.18) for $\mathrm{PM}_{10}$ to 1.20 (1.10-1.32) for $\mathrm{NO}_{2}$ ) per interquartile range increase) that were rather persistent with age. Similar associations were observed with more recent exposure defined as exposure at the current home address. In two-pollutant models with particulate matter, associations with $\mathrm{NO}_{2}$ persisted.

Conclusions: Exposure to air pollution, especially from motorised traffic, early in life may have long-term consequences for asthma development, as it is associated with an increased risk of developing asthma through childhood and adolescence into early adulthood. 


\section{Introduction}

Asthma is one of the major noncommunicable diseases and has been estimated to affect 339 million people worldwide [1]. It is a heterogeneous disease, usually characterised by chronic airway inflammation and defined by a history of respiratory symptoms that vary over time and in intensity, together with variable expiratory airflow limitation [2]. Asthma can develop at any age, but most asthmatics develop the first symptoms in childhood [2]. Both genetic and environmental factors contribute to the disease [1].

There is growing evidence from prospective cohort studies that exposure to ambient air pollution increases the risk of developing asthma in children [3,4], and some evidence for such a relationship in adults [512]. However, the impact of air pollution on asthma development during the transition from adolescence to adulthood is currently unclear. Some of the studies in children $[13,14]$ and most of the studies in adults include some adolescents and/or young adults, but participants aged 17-20 years are generally underrepresented and air pollution effect estimates are not presented for that specific age group. Another limitation of the studies in adults is the lack of historical exposures before enrolment into the study, making it impossible to study the relevance of exposure at different time points.

Several mechanisms have been proposed for how air pollution contributes to asthma development, including oxidative stress and damage, airway remodelling, inflammatory pathways and immunological responses, and enhancement of respiratory sensitisation to aeroallergens [15].

This study extends previous analyses up to the age of 14 years within the prospective PIAMA (Prevention and Incidence of Asthma and Mite Allergy) birth cohort study [16]. We added data collected at ages 17 and 20 years and assessed the long-term overall and age-specific effects of outdoor air pollution exposure early in life and more recently on incident asthma from birth until the age of 20 years.

\section{Materials and methods}

\section{Study design and study population}

Details on the PIAMA birth cohort study have been published elsewhere $[17,18]$. In brief, pregnant women were recruited from the general population through antenatal clinics in the north, west and centre of the Netherlands in 1996-1997. The study started with 3963 newborns. Parents completed questionnaires on demographic factors, risk factors for asthma and respiratory symptoms at birth, at the child's ages of 3 months and 1 year and then annually until the age of 8 years. At ages 11, 14 and 17 years, both the parents and the participants themselves completed questionnaires, and at age 20 years only the participants completed questionnaires. For the present analysis, all participants with data on incident asthma and data on air pollution exposure at the birth address and/or current address for at least one of the questionnaire surveys were included ( $n=3687$ ), of which $90 \%$ (3314 out of 3687 ) had data for seven or more of the 12 questionnaire surveys, and only few (59 (3\%) out of 3687) had data for a single questionnaire survey only.

The institutional review boards of the participating institutes approved the study protocol, and written informed consent was obtained from the parents or legal guardians of all participants.

\section{Definition of asthma}

Information on the participant's respiratory health was collected by repeated questionnaires from birth until age 20 years. Asthma was defined as a positive answer to at least two of the three following questions: 1) "Has a doctor ever diagnosed asthma in your child? (age 20 years: Has a doctor ever told you that you have asthma?)", 2) "Has your child (age 20 years: Have you) had wheezing or whistling in the chest in the last 12 months?", 3) "Has your child (age 20 years: Have you) been prescribed asthma medication during the last 12 months?"; this definition has been developed by a panel of experts within the Mechanisms of the Development of Allergy (MeDALL) consortium [19]. Incident asthma was defined as positive the first time a participant fulfilled the criteria for asthma if participants had nonmissing data for all previous follow-ups. Incident asthma was defined as negative if a participant did not fulfil the criteria in the respective year and all previous years. Data for participants with missing information on asthma for one or more follow-ups were right censored and incident asthma was defined missing from the first follow-up with missing data onwards.

\section{Air pollution exposure assessment}

Annual average air pollution concentrations at the participants' birth address and current home addresses at the different follow-ups were estimated by land-use regression models described elsewhere [20, 21] and in the supplementary material. In brief, three 2-week air pollution monitoring campaigns were performed in 2008-2010 and nitrogen dioxide $\left(\mathrm{NO}_{2}\right)$, particulate matter with a diameter $<2.5 \mu \mathrm{m}\left(\mathrm{PM}_{2.5}\right),<10 \mu \mathrm{m}$ $\left(\mathrm{PM}_{10}\right)$ and 2.5-10 $\mu \mathrm{m}\left(\mathrm{PM}_{\text {coarse }}\right)$, and "soot" $\left(\mathrm{PM}_{2.5}\right.$ absorbance, determined as the reflectance of $\mathrm{PM}_{2.5}$ filters), were measured and results were averaged to estimate the annual average [21]. Predictor variables 
on nearby traffic, population/household density and land use derived from geographic information systems were evaluated to explain spatial variation in annual average concentrations as described in the supplementary material. Regression models (supplementary table E1) were developed and then used to estimate annual average air pollution concentrations at the participants' home addresses.

\section{Covariates}

Covariates were selected a priori based on literature. Sex, maternal and paternal asthma and/or hay fever (yes/no), Dutch nationality (both parents being born in the Netherlands, yes/no), parental education (maximum educational level attained by the mother or father, low/medium/high), breastfeeding at 12 weeks (yes/no), older siblings (yes/no) and maternal smoking during pregnancy (yes/no) were obtained from questionnaires completed during pregnancy or the child's first year of life; daycare attendance (yes/ no) was obtained from the 2-year questionnaire. Smoking in the participant's home (yes/no), mould/damp spots in the living room and/or participant's bedroom (yes/no) and gas cooking (yes/no) were obtained from the parental questionnaires from birth until age 17 years and questionnaires completed by the participants themselves at age 20 years. Information on active smoking of the participants (at least once a week, yes/no) was obtained from the questionnaires completed by the participants from the age of 14 years onwards.

\section{Statistical analysis}

Associations of air pollution exposure with asthma incidence from birth until age 20 years were analysed with discrete-time hazard models [22]. In brief, we divided the follow-up until age 20 years into 12 discrete periods (i.e. periods in between questionnaires, that is periods of 1 year until age 8 years and periods of 3 years afterwards) and modelled the conditional probability of developing asthma in each discrete time period, given that a participant did not have asthma in any earlier time period in relation to air pollution exposure. Separate analyses were performed with early-life exposure (defined as exposure at the birth address) for all time periods and more recent exposure (defined as exposure at the current home address) at a specific follow-up for the respective period, taking into account changes in exposure due to changes in address. Time-varying confounders (mould/damp spots, use of gas cooking, passive and active smoking) were selected from questionnaires that coincided best with the exposure period. Age- and sex-specific effects were obtained by adding exposure-age and exposure-sex interaction terms, respectively, to the models. Attrition bias is a concern in cohorts with long follow-ups and was explored as part of a sensitivity analysis among those with nearly complete follow-up ( $\geqslant 11$ out of the 12 questionnaires). We defined more recent exposure for a specific period, as exposure at the home address at the time of questionnaire completion (i.e. at the end of that period) and temporality might be a concern for those who changed address between follow-ups. Therefore, we assessed to what extent associations with more recent exposure were sensitive to our definition of more recent exposure by defining more recent exposure as exposure at the home address at the preceding follow-up. Since asthma is difficult to diagnose in very young children, we restricted our analysis to data from age 4 years onward as part of a sensitivity analysis to assess to what extent associations were driven the high incidence before the age of 4 years in our cohort.

Air pollution levels were entered one by one (unless stated otherwise) as continuous variables without transformation in the analyses described above. All associations are presented as odds ratios (95\% CI) for an interquartile range increase in exposure at the birth address. All analyses were performed with the Statistical Analysis System (version 9.4; SAS, Cary, NC, USA).

\section{Results}

Population characteristics

The study sample consists of $93 \%$ of the baseline cohort. Differences in characteristics between all participants and those who completed the 20-year questionnaire (2135 (58\%) out of 3678) were small (supplementary table E2). Characteristics of the study population are presented in table 1. Age-specific prevalence and incidence of asthma are presented in table 2; age- and sex-specific incidence are presented in supplementary figure E1.

\section{Air pollution exposure}

Distributions of exposures at the birth address and home addresses at the 20-year follow-up were very similar (table 3). Exposure contrasts were larger for $\mathrm{NO}_{2}$ and $\mathrm{PM}_{2.5}$ absorbance (maximum-minimum ratios 3.5-9.6) than for particle mass concentrations (maximum-minimum ratios 1.4-1.9). Correlations between exposures at the birth address and at home addresses at the different follow-ups were moderate to high until the age of age 17 years and much lower at 20 years, e.g. correlations ranged from 0.76 to 0.97 for $\mathrm{NO}_{2}$ and from 0.58 to 0.96 for $\mathrm{PM}_{10}$ until the age of 17 years and decreased to 0.55 and 0.38 , 


\begin{tabular}{|c|c|}
\hline Female & $1780 / 3687(48.3)$ \\
\hline Maternal asthma and/or hay fever & $881 / 3652(24.1)$ \\
\hline Paternal asthma and/or hay fever & $911 / 3658(24.9)$ \\
\hline Dutch nationality & $3190 / 3521(90.6)$ \\
\hline High maternal education & $1298 / 3678$ (35.3) \\
\hline High paternal education & $1458 / 3637(40.1)$ \\
\hline Breastfeeding ( $\geqslant 12$ weeks) & $1627 / 3463(47.0)$ \\
\hline Older siblings & $1860 / 3678(50.6)$ \\
\hline Daycare centre attendance ${ }^{\#}$ & $2040 / 3538(57.7)$ \\
\hline Mother smoked during pregnancy & $626 / 3652(17.1)$ \\
\hline \multicolumn{2}{|l|}{ Smoking at child's home ${ }^{\pi}$} \\
\hline Early life $^{+}$ & $912 / 3686(24.7)$ \\
\hline Age 20 years & $186 / 2127(8.7)$ \\
\hline \multicolumn{2}{|l|}{ Active smoking at least once a week ${ }^{\S}$} \\
\hline Age 14 years & $119 / 2431(4.9)$ \\
\hline Age 20 years & $426 / 2127(20.0)$ \\
\hline \multicolumn{2}{|l|}{ Use of natural gas for cooking } \\
\hline Early life ${ }^{+}$ & $3028 / 3674(82.4)$ \\
\hline Age 20 years & $1564 / 2127(73.5)$ \\
\hline \multicolumn{2}{|l|}{ Mould/damp spots in participant's home } \\
\hline Early life ${ }^{+}$ & $300 / 3643(8.2)$ \\
\hline Age 20 years & $242 / 2127(11.4)$ \\
\hline \multicolumn{2}{|l|}{ Furry pets in participant's home } \\
\hline Early life $^{+}$ & $1720 / 3677(46.8)$ \\
\hline Age 20 years & $877 / 2127(41.2)$ \\
\hline Change of address between birth and most recent follow-up & $2637 / 3687(71.5)$ \\
\hline
\end{tabular}

Data are presented as $\mathrm{n} / \mathrm{N}(\%) . \mathrm{n}=3687 .{ }^{*}$ : during second year of life; ${ }^{\text {ๆ: }}$ defined as parental smoking until and including age 17 years and any smoking at age 20 years; ${ }^{+}$: during first year of life; ${ }^{\S}$ : at age $\geqslant 14$ years.

respectively, at 20 years (supplementary figure E2). Correlations between exposures at the same age were highest for $\mathrm{NO}_{2}$ and $\mathrm{PM}_{2.5}$ absorbance ( $\left.\mathrm{r}=0.88-0.91\right)$.

Air pollution and asthma incidence

Overall, after adjustment for potential confounders, we found a significantly higher incidence of asthma until the age of 20 years among participants with higher exposure to all pollutants at the birth address with odds ratios $(95 \% \mathrm{CI})$ ranging from 1.09 (1.01-1.18) for $\mathrm{PM}_{10}$ to 1.20 (1.10-1.32) for $\mathrm{NO}_{2}$ per interquartile range increase in exposure (table 4). In addition, incident asthma was found to be significantly associated with exposure at the home address at the time of the follow-up for all pollutants except $\mathrm{PM}_{10}$, with odds ratios similar to those for exposures at the birth address.

\section{TABLE 2 Age-specific prevalence and incidence of asthma}

\begin{tabular}{lcc} 
Age years & Prevalence & Incidence \\
\hline $\mathbf{1}$ & $221 / 3687(6.0)$ & $221 / 3687(6.0)$ \\
$\mathbf{2}$ & $213 / 3551(6.0)$ & $80 / 3346(2.4)$ \\
$\mathbf{3}$ & $353 / 3503(10.1)$ & $201 / 3172(6.3)$ \\
$\mathbf{4}$ & $291 / 3393(8.6)$ & $79 / 2838(2.8)$ \\
$\mathbf{5}$ & $279 / 3360(8.3)$ & $56 / 2652(2.1)$ \\
$\mathbf{6}$ & $273 / 3336(8.2)$ & $39 / 2525(1.5)$ \\
$\mathbf{7}$ & $219 / 3247(6.7)$ & $34 / 2411(1.4)$ \\
$\mathbf{8}$ & $230 / 3194(7.2)$ & $25 / 2285(1.1)$ \\
$\mathbf{1 1}$ & $174 / 2570(6.8)$ & $23 / 1824(1.3)$ \\
$\mathbf{1 4}$ & $157 / 2271(6.9)$ & $28 / 1491(1.9)$ \\
$\mathbf{1 7}$ & $93 / 1827(5.1)$ & $11 / 1188(0.9)$ \\
$\mathbf{2 0}$ & $157 / 2135(7.4)$ & $16 / 1031(1.6)$ \\
\hline Data are presented as n/N (\%). & & \\
\hline
\end{tabular}


TABLE 3 Distribution of estimated annual average air pollution levels at the participants' birth addresses and home addresses at the most recent (20-year) follow-up

\begin{tabular}{|c|c|c|c|c|c|c|c|c|c|c|}
\hline & \multicolumn{5}{|c|}{ Birth address } & \multicolumn{5}{|c|}{ 20-year follow-up address } \\
\hline & Mean士sD & Min & P50 & $\operatorname{Max}$ & IQR & Mean士sD & Min & P50 & Max & IQR \\
\hline Subjects $n$ & \multicolumn{5}{|c|}{3674} & \multicolumn{5}{|c|}{2009} \\
\hline $\mathrm{PM}_{2.5}$ absorbance $10^{-5} \cdot \mathrm{m}^{-1}$ & $1.26 \pm 0.27$ & 0.85 & 1.25 & 3.11 & 0.31 & $1.31 \pm 0.29$ & 0.85 & 1.27 & 2.95 & 0.31 \\
\hline $\mathrm{PM}_{2.5} \mu \mathrm{g} \cdot \mathrm{m}^{-3}$ & $16.4 \pm 0.7$ & 15.3 & 16.5 & 21.1 & 1.2 & $16.5 \pm 0.8$ & 14.9 & 16.5 & 21.1 & 1.0 \\
\hline $\mathrm{PM}_{10} \mu \mathrm{g} \cdot \mathrm{m}^{-3}$ & $25.0 \pm 1.2$ & 23.7 & 24.7 & 33.2 & 1.2 & $25.2 \pm 1.3$ & 23.7 & 24.9 & 32.5 & 1.5 \\
\hline
\end{tabular}

IQR: interquartile range; $\mathrm{NO}_{2}$ : nitrogen dioxide; $\mathrm{PM}_{2.5}$ : particulate matter with a diameter $<2.5 \mu \mathrm{m} ; \mathrm{PM}_{10}$ : particulate matter with a diameter $<10 \mu \mathrm{m}$; $\mathrm{PM}_{\text {coarse }}$ : particulate matter with a diameter $2.5-10 \mu \mathrm{m}$.

Age-specific association estimates from analyses with exposure-age interaction terms had wide confidence intervals because of the relatively low number of cases per year, but indicate that associations tend to be generally positive for all ages, except for age 7 years, for which association estimates where consistently negative. Association estimates for exposures at the birth address were consistent in size from the age of 4 years onwards (with the exception of age 7 years) for $\mathrm{NO}_{2}$ and $\mathrm{PM}_{2.5}$ absorbance, but not for $\mathrm{PM}_{2.5}, \mathrm{PM}_{10}$ and $\mathrm{PM}_{\text {coarse }}$ (figure 1). Age-specific associations with more recent exposure defined as exposure at the current address at the time of follow-up were less consistent between ages (supplementary figure E3). None of the exposure-age interactions were statistically significant ( $p$-values from 0.3910 to 0.7869 ).

Associations of asthma incidence with air pollution tended to be stronger in females than in males (supplementary figure E4), but exposure-sex interactions were not statistically significant ( $\mathrm{p}$-value was 0.0510 for $\mathrm{NO}_{2}$ at the birth address and $>0.19$ otherwise).

Findings from two-pollutant models (supplementary table E3) suggest that associations with $\mathrm{NO}_{2}$ are robust against adjustment for particulate matter mass, i.e. $\mathrm{PM}_{2.5}, \mathrm{PM}_{10}$ and $\mathrm{PM}_{\text {coarse }}$, and that associations with particulate matter mass diminish or disappear completely after adjustment for $\mathrm{NO}_{2}$. Two-pollutant

TABLE 4 Crude and adjusted overall associations of air pollution exposure early in life (i.e. at the birth address) and more recently (i.e. at the current address at the time of follow-up) with asthma incidence until the age of 20 years

\begin{tabular}{|c|c|c|c|c|}
\hline \multirow[t]{2}{*}{ Pollutant (increment) } & \multicolumn{2}{|c|}{ Crude } & \multicolumn{2}{|c|}{ Adjusted $^{\#}$} \\
\hline & OR $(95 \% \mathrm{CI})$ & p-value & OR $(95 \% \mathrm{CI})$ & p-value \\
\hline \multicolumn{5}{|l|}{ Birth address } \\
\hline Subjects $n$ & 3674 & & 3141 & \\
\hline $\mathrm{NO}_{2}\left(9.2 \mu \mathrm{g} \cdot \mathrm{m}^{-3}\right)$ & $1.19(1.09-1.29)$ & 0.0001 & $1.20(1.10-1.32)$ & 0.0001 \\
\hline $\mathrm{PM}_{2.5}$ absorbance $\left(0.310^{-5} \cdot \mathrm{m}^{-1}\right)$ & $1.11(1.03-1.20)$ & 0.0046 & $1.12(1.03-1.22)$ & 0.0056 \\
\hline $\mathrm{PM}_{2.5}\left(1.2 \mu \mathrm{g} \cdot \mathrm{m}^{-3}\right)$ & $1.16(1.04-1.30)$ & 0.0084 & $1.15(1.02-1.30)$ & 0.0222 \\
\hline $\mathrm{PM}_{10}\left(1.2 \mu \mathrm{g} \cdot \mathrm{m}^{-3}\right)$ & 1.07 (1.00-1.15) & 0.0387 & 1.09 (1.01-1.18) & 0.0221 \\
\hline $\mathrm{PM}_{\text {coarse }}\left(0.9 \mu \mathrm{g} \cdot \mathrm{m}^{-3}\right)$ & $1.09(1.02-1.16)$ & 0.0067 & $1.12(1.04-1.20)$ & 0.0015 \\
\hline \multicolumn{5}{|l|}{ Current address } \\
\hline Subjects $n$ & 3686 & & 3191 & \\
\hline $\mathrm{NO}_{2}\left(9.2 \mu \mathrm{g} \cdot \mathrm{m}^{-3}\right)$ & $1.12(1.03-1.24)$ & 0.0081 & 1.15 (1.04-1.27) & 0.0080 \\
\hline $\mathrm{PM}_{2.5}$ absorbance $\left(0.310^{-5} \cdot \mathrm{m}^{-1}\right)$ & $1.09(1.01-1.18)$ & 0.0358 & $1.12(1.03-1.23)$ & 0.0124 \\
\hline $\mathrm{PM}_{2.5}\left(1.2 \mu \mathrm{g} \cdot \mathrm{m}^{-3}\right)$ & $1.15(1.02-1.29)$ & 0.0220 & $1.19(1.04-1.36)$ & 0.0094 \\
\hline $\mathrm{PM}_{10}\left(1.2 \mu \mathrm{g} \cdot \mathrm{m}^{-3}\right)$ & 1.05 (0.97-1.13) & 0.2445 & 1.07 (0.99-1.17) & 0.0862 \\
\hline $\mathrm{PM}_{\text {coarse }}\left(0.9 \mu \mathrm{g} \cdot \mathrm{m}^{-3}\right)$ & $1.07(1.00-1.15)$ & 0.0498 & $1.11(1.02-1.20)$ & 0.0114 \\
\hline \multicolumn{5}{|c|}{ 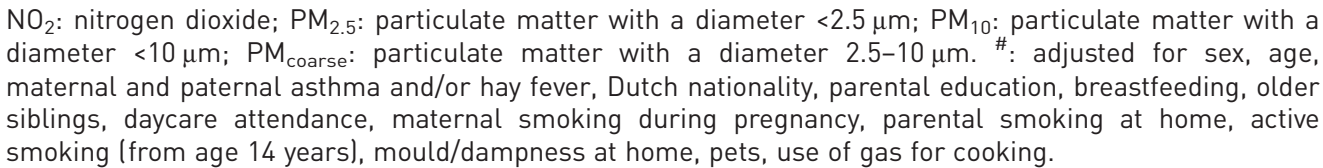 } \\
\hline
\end{tabular}



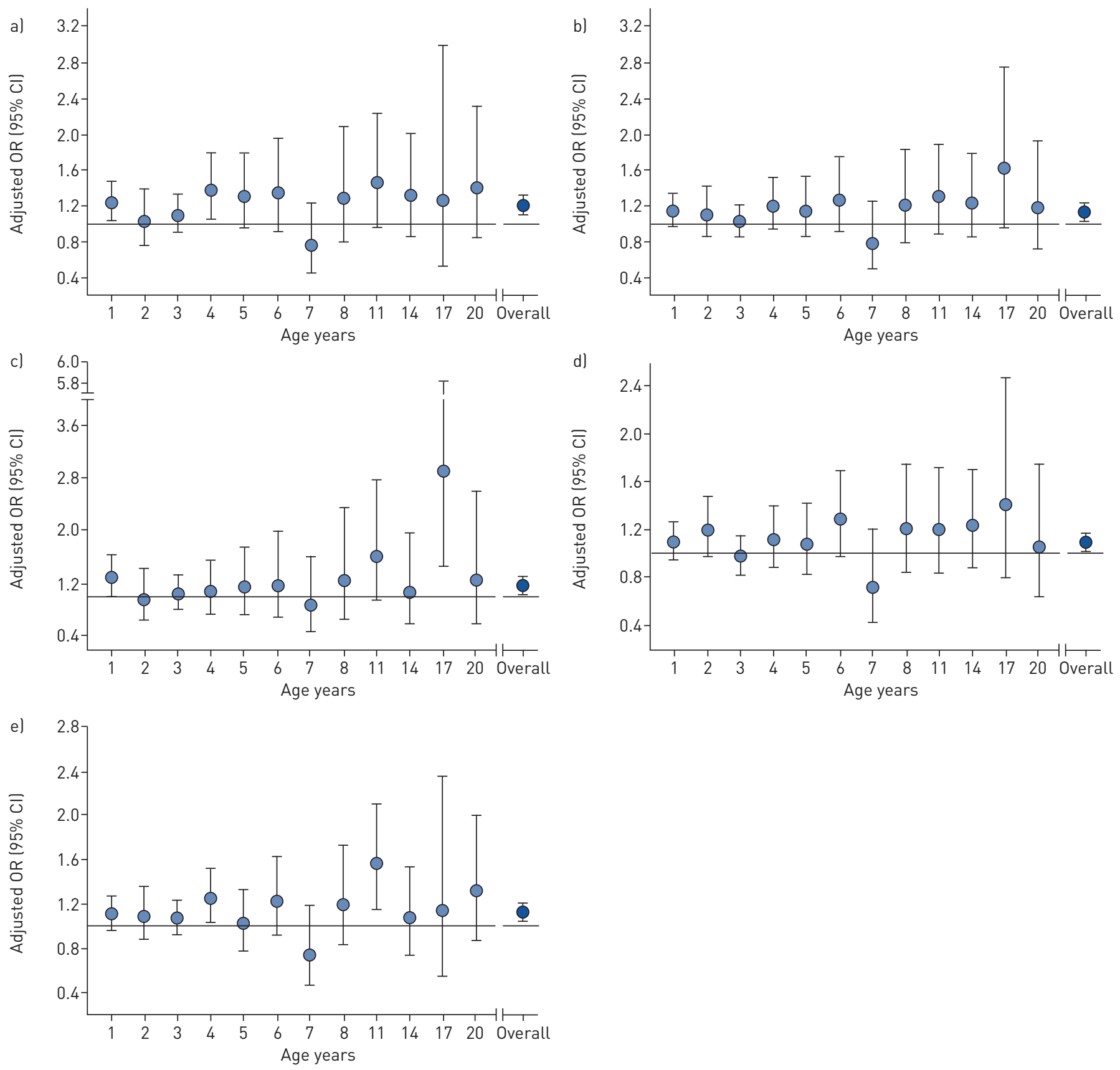

FIGURE 1 Adjusted ${ }^{\#}$ age-specific associations of air pollution exposure early in life (i.e. at the birth address) with asthma incidence until age 20 years ( $n=3141$ subjects). a) nitrogen dioxide; b) particulate matter with a diameter $<2.5 \mu \mathrm{m}\left(\mathrm{PM}_{2.5}\right)$ absorbance; c) $P M_{2.5} ;$ d) particulate matter with a diameter $<10 \mu \mathrm{m}$; e) particulate matter with a diameter $2.5-10 \mu \mathrm{m}$. \# : adjusted for sex, maternal and paternal asthma and/or hay fever, Dutch nationality, parental education, breastfeeding, older siblings, daycare attendance, maternal smoking during pregnancy, parental smoking at home, active smoking (from age 14 years), mould/dampness at home, pets, use of gas for cooking.

models with $\mathrm{PM}_{2.5}$ absorbance did not produce valid results (variance inflation factors range from 4.0 to 5.5) due to the high correlations with all other pollutants.

Results remained largely unchanged, except for larger confidence intervals when restricted to the almost 1700 participants with nearly complete follow-up (supplementary figures E5 and E6). Findings were not sensitive to the definition of more recent exposure; associations remained unchanged when we used exposure at the home address at the time of the preceding instead of the same follow-up (supplementary table E4). Association estimates remained stable or were slightly larger when we restricted our analysis to ages $\geqslant 4$ years, but confidence intervals became wider due to the smaller number of cases (supplementary table E5). 


\section{Discussion}

The present study suggests that exposure to air pollution is associated with the development of asthma through childhood and adolescence into early adulthood.

This study extends previous work within this and other European birth cohorts regarding the impact of outdoor air pollution on asthma development in children and adolescents up to the age of 14-16 years [16] and closes the gap between findings from these and other children's cohorts and findings from adult cohorts [5-12]. Although statistical power to assess age-specific associations is limited in our cohort, association estimates for $\mathrm{NO}_{2}$ and $\mathrm{PM}_{2.5}$ absorbance at the birth address are rather stable from age of 4 years onwards and do not seem to decrease in early adulthood. Larger (consortia of) cohorts are needed to confirm our findings. To our knowledge only few other studies assessed the impact of air pollution on asthma development through childhood and adolescence into young adulthood $[13,14,23]$ and none of them looked into age-specific associations. The study of the associations between $\mathrm{NO}_{2}$ and asthma incidence within the Southern California Children's Health Study (CHS) by JERRETT et al. [13] clearly lacks statistical power for such an analysis, with only 30 cases in total among 200 participants followed from age 10-18 years, but within the case-control study by Nishimura et al. [14] performed among Latinos and African Americans from the USA and Puerto Rico, with almost 600 cases aged $\geqslant 15$ years, this might have been possible. The same holds for the study by GARCIA et al. [23] which showed a decline in asthma incidence with reductions in air pollution levels from 1993 to 2014 among >4000 participants of the CHS aged 10-18 years. The overall association estimates obtained from the present study are somewhat stronger than those reported for children and adolescents up to age 18 years by JERRETT et al. [13], Nishimura et al. [14] and a recent review [3], which correspond to risk ratios (95\% CI) of $1.09(1.02-1.16), 1.07$ (1.02-1.12) and 1.05 (1.02-1.07), respectively, for a $9.2 \mu \mathrm{g} \cdot \mathrm{m}^{-3}$ increase in $\mathrm{NO}_{2}$ levels. The less consistent associations between incident asthma and air pollution levels at the birth address until the age of 4 years may be explained by the fact that asthma is difficult to diagnose in very young children [24]. Thus, outcome misclassification, which may also explain in part the higher incidence for that age group as compared to older ages, is a concern. Since neither the participants nor their physicians were aware of the exact air pollution exposure levels, outcome misclassification is probably nondifferential and bias in association estimates (if any) would be towards the null. As in previous analyses [16], differences in associations between males and females were not statistically significant. Associations with $\mathrm{NO}_{2}$ and $\mathrm{PM}_{2.5}$ absorbance, which are more traffic-related than particulate matter mass concentrations, confirm the role of motorised traffic in these associations suggested by findings of earlier studies showing associations between living near major roads and asthma incidence in children [25] and adults [9]. Due to their high correlation, owing to the fact that motorised traffic is a major source of both $\mathrm{NO}_{2}$ and $\mathrm{PM}_{2.5}$ absorbance, it is impossible to disentangle the contributions of these two exposures to asthma development. Consequently, it remains unclear whether associations are attributable to $\mathrm{NO}_{2}$ itself as suggested [26, 27], or whether $\mathrm{NO}_{2}$ acts as a surrogate for a complex mixture of air pollutants. Associations with $\mathrm{NO}_{2}$ were independent of particle mass concentrations $\left(\mathrm{PM}_{2.5}, \mathrm{PM}_{10}\right.$ and $\left.\mathrm{PM}_{\text {coarse }}\right)$ in our study, whereas associations with particle mass diminish or disappear after adjustment for $\mathrm{NO}_{2}$. Two-pollutant models behaved slightly differently for early-life and more recent exposures. Associations with $\mathrm{NO}_{2}$ at the birth address, but not associations with $\mathrm{NO}_{2}$ at the current address, tended to become stronger in two-pollutant models; associations with particle mass concentrations (except $\mathrm{PM}_{10}$ ) at the current address were halved, whereas associations with particle mass concentrations at the birth address disappeared completely after adjustment for $\mathrm{NO}_{2}$. The reasons for this are not clear as correlations between pollutants are high and almost identical for the birth and current addresses.

A major strength of the present study over previous studies in adults is the availability of residential histories and exposure histories since birth. This enables us to look into the relevance of exposure at different time points, i.e. exposure early in life defined as exposure at the birth address versus more recent exposure defined as exposure at the address at each follow-up. These analyses with regard to the relevance of the timing of exposure become increasingly interesting as more and more participants move out of their parental home ( $40 \%$ of the current study sample at the time of the 20 -year follow-up) and correlations of more recent exposures with early life exposures, which have been high for most of the follow-up, especially for $\mathrm{NO}_{2}$ and $\mathrm{PM}_{2.5}$ absorbance (e.g. $\mathrm{r}=0.76-0.98$ until age 17 years for $\mathrm{NO}_{2}$ ), finally dropped to values between 0.38 for $\mathrm{PM}_{10}$ and 0.55 for $\mathrm{NO}_{2}$. Nevertheless, the relevance of early life over recent exposure remains unclear: mutually adjusted models with early-life and more recent exposure are not feasible yet, as for most of the follow-up so far, correlations with exposure at the birth address are high and the number of incident cases from the 20-year follow-up is too small $(n=16)$ to provide meaningful results. These analyses require a longer follow-up or data from multiple cohorts.

Several studies reported stronger associations for nonatopic asthma than for atopic asthma [16, 28] or associations with nonatopic asthma only $[14,29]$. A limitation of the present study is the lack of statistical 
power to analyse associations with atopic and nonatopic asthma separately, as measurements of specific IgE to common inhalant allergens were limited to subsets of the current study population and specific ages $(n=685, n=1655, n=1269$ and $n=738$ participants at ages $4,8,12$ and 16 years, respectively). With between $41 \%$ and $53 \%$ of the subjects being sensitised to at least one of the allergens tested, numbers of atopic and nonatopic incident asthma cases $(n=7$ and $n=13$, respectively, at most per age) were too small to provide any meaningful results, again requiring larger or multiple cohorts. Attrition bias is a concern in studies with long follow-ups. However, population characteristics were not very different at age 20 years and associations with air pollution were very similar among those with almost complete follow-up. Generalisability to the Dutch general population may be a concern, as children of highly educated parents and children of Dutch parents are overrepresented [18]. However, at present there is no evidence for a different susceptibility of these groups to the effects of air pollution. Generalisability beyond the Dutch general population may also be a concern, but findings from a recent meta-analysis [3] found no regional heterogeneity in associations of childhood asthma with air pollution. Another limitation is the use of purely spatial land-use regression models for estimation of the participants' residential exposure. The models were developed using data from air pollution measurement campaigns performed between 2008 and 2010 and applied to the residential histories of our study participants over a period of 20 years starting in 1996/1997. This means that we used the models to forecast and back-cast exposures for periods of about 11 years, which may have resulted in exposure misclassification and some bias in exposureresponse relationships. However, spatial contrasts have been shown to be stable over periods of $\geqslant 7$ years for $\mathrm{NO}_{2}$ in seven areas including the Netherlands [30-32] and over even longer periods for black smoke in the United Kingdom [33]. Nevertheless, by using purely spatial land-use regression models, we did not account for long-term trends in air pollution levels and may have underestimated exposure contrasts for the earlier years and overestimated contrasts for the more recent years, as $\mathrm{NO}_{2}$ and $\mathrm{PM}_{10}$ concentrations have decreased in the Netherlands over recent decades $[34,35]$.

In conclusion, exposure to air pollution, especially from motorised traffic, early in life may have long-term consequences for asthma development as it is associated with an increased risk of developing asthma through childhood and adolescence into early adulthood.

Acknowledgements: The authors would like to thank the PIAMA participants and parents who contributed to the study, and Marjan Tewis (Institute for Risk Assessment Sciences, Utrecht University, Utrecht, the Netherlands) for data management.

Conflict of interest: U. Gehring has nothing to disclose. A.H. Wijga has nothing to disclose. G.H. Koppelman reports grants from Lung Foundation of the Netherlands, during the conduct of the study; grants from Tetri Foundation, Ubbo Emmius Foundation, TEVA the Netherlands, Vertex and GSK, institutional fees from GSK, outside the submitted work. J.M. Vonk has nothing to disclose. H.A. Smit has nothing to disclose. B. Brunekreef has nothing to disclose.

Support statement: The research leading to these results has received funding from Dutch Lung Foundation (project number 4.1.14.001). In addition, the PIAMA study was supported by The Netherlands Organization for Health Research and Development; The Netherlands Organization for Scientific Research; The Netherlands Asthma Fund; The Netherlands Ministry of Spatial Planning, Housing, and the Environment; and The Netherlands Ministry of Health, Welfare, and Sport. Ulrike Gehring was supported by a Grant of The Netherlands Organization for Scientific Research. Funding information for this article has been deposited with the Crossref Funder Registry.

\section{References}

1 Global Asthma Network. The Global Asthma Report 2018. Auckland, New Zealand, Global Asthma Network, 2018. www.globalasthmanetwork.org

2 Global Initiative for Asthma. Global Strategy for Asthma Management and Prevention. 2019. www.ginasthma.org Date last accessed: January 23, 2020.

3 Khreis H, Kelly C, Tate J, et al. Exposure to traffic-related air pollution and risk of development of childhood asthma: a systematic review and meta-analysis. Environ Int 2017; 100: 1-31.

4 Bowatte G, Lodge C, Lowe AJ, et al. The influence of childhood traffic-related air pollution exposure on asthma, allergy and sensitization: a systematic review and a meta-analysis of birth cohort studies. Allergy 2015; 70: 245-256.

5 Jacquemin B, Sunyer J, Forsberg B, et al. Association between modelled traffic-related air pollution and asthma score in the ECRHS. Eur Respir J 2009; 34: 834-842.

6 Young MT, Sandler DP, DeRoo LA, et al. Ambient air pollution exposure and incident adult asthma in a nationwide cohort of U.S. women. Am J Respir Crit Care Med 2014; 190: 914-921.

7 Jacquemin B, Siroux V, Sanchez M, et al. Ambient air pollution and adult asthma incidence in six European cohorts (ESCAPE). Environ Health Perspect 2015; 123: 613-621.

8 Weichenthal S, Bai L, Hatzopoulou M, et al. Long-term exposure to ambient ultrafine particles and respiratory disease incidence in in Toronto, Canada: a cohort study. Environ Health 2017; 16: 64.

9 Bowatte G, Lodge CJ, Knibbs LD, et al. Traffic-related air pollution exposure is associated with allergic sensitization, asthma, and poor lung function in middle age. J Allergy Clin Immunol 2017; 139: 122-129.

10 Modig L, Torén K, Janson C, et al. Vehicle exhaust outside the home and onset of asthma among adults. Eur Respir J 2009; 33: 1261-1267. 
11 Modig L, Järvholm B, Rönnmark E, et al. Vehicle exhaust exposure in an incident case-control study of adult asthma. Eur Respir J 2006; 28: 75-81.

12 Künzli N, Bridevaux PO, Liu LJ, et al. Traffic-related air pollution correlates with adult-onset asthma among never-smokers. Thorax 2009; 64: 664-670.

13 Jerrett $\mathrm{M}$, Shankardass $\mathrm{K}$, Berhane $\mathrm{K}$, et al. Traffic-related air pollution and asthma onset in children: a prospective cohort study with individual exposure measurement. Environ Health Perspect 2008; 116: 1433-1438.

14 Nishimura KK, Galanter JM, Roth LA, et al. Early-life air pollution and asthma risk in minority children. The GALA II and SAGE II studies. Am J Respir Crit Care Med 2013; 188: 309-318.

15 Gowers AM, Cullinan P, Ayres JG, et al. Does outdoor air pollution induce new cases of asthma? Biological plausibility and evidence; a review. Respirology 2012; 17: 887-898.

16 Gehring U, Wijga AH, Hoek G, et al. Exposure to air pollution and development of asthma and rhinoconjunctivitis throughout childhood and adolescence: a population-based birth cohort study. Lancet Respir Med 2015; 3: 933-942.

17 Brunekreef B, Smit J, de Jongste J, et al. The prevention and incidence of asthma and mite allergy (PIAMA) birth cohort study: design and first results. Pediatr Allergy Immunol 2002; 13: Suppl. 15, 55-60.

18 Wijga $\mathrm{AH}$, Kerkhof $\mathrm{M}$, Gehring $\mathrm{U}$, et al. Cohort profile: the prevention and incidence of asthma and mite allergy (PIAMA) birth cohort. Int J Epidemiol 2014; 43: 527-535.

19 Pinart M, Benet M, Annesi-Maesano I, et al. Comorbidity of eczema, rhinitis, and asthma in IgE-sensitised and non-IgE-sensitised children in MeDALL: a population-based cohort study. Lancet Respir Med 2014; 2: 131-140.

20 Beelen R, Hoek G, Vienneau D, et al. Development of $\mathrm{NO}_{2}$ and $\mathrm{NO}_{\mathrm{x}}$ land use regression models for estimating air pollution exposure in 36 study areas in Europe - The ESCAPE project. Atmos Environ 2013; 72: 10-23.

21 Eeftens $\mathrm{M}$, Beelen R, de Hoogh $\mathrm{K}$, et al. Development of land use regression models for $\mathrm{PM}_{2.5}, \mathrm{PM}_{25}$ absorbance, $\mathrm{PM}_{10}$ and $\mathrm{PM}_{\text {coarse }}$ in 20 European study areas; results of the ESCAPE project. Environ Sci Technol 2012; 46: 11195-11205.

22 Singer JD, Willett JB. Applied Longitudinal Data Analysis: Modeling Change and Event Occurrence. New York, Oxford University Press, 2003.

23 Garcia E, Urman R, Berhane $\mathrm{K}$, et al. Effects of policy-driven hypothetical air pollutant interventions on childhood asthma incidence in southern California. Proc Natl Acad Sci USA 2019; 116: 15883-15888.

24 Martinez FD, Wright AL, Taussig LM, et al. Asthma and wheezing in the first six years of life. The Group Health Medical Associates. N Engl J Med 1995; 332: 133-138.

25 McConnell R, Berhane K, Yao L, et al. Traffic, susceptibility, and childhood asthma. Environ Health Perspect 2006; 114: 766-772.

26 World Health Organization (WHO) Regional Office for Europe. 2013. Review of Evidence on Health Aspects of Air Pollution - REVIHAAP Project Date last accessed: January 23, 2020. www.euro.who.int/_data/assets/pdf_file/ 0004/193108/REVIHAAP-Final-technical-report.pdf.

27 US Environmental Protection Agency. Integrated Science Assessment for Oxides of Nitrogen - Health Criteria. Research Triangle Park, NC, U.S. Environmental Protection Agency, 2016.

28 Mölter A, Simpson A, Berdel D, et al. A multicentre study of air pollution exposure and childhood asthma prevalence: the ESCAPE project. Eur Respir J 2015; 45: 610-624.

29 Gruzieva O, Bergström A, Hulchiy O, et al. Exposure to air pollution from traffic and childhood asthma until 12 years of age. Epidemiology 2013; 24: 54-61.

30 Cesaroni G, Porta D, Badaloni C, et al. Nitrogen dioxide levels estimated from land use regression models several years apart and association with mortality in a large cohort study. Environ Health 2012; 11: 48.

31 Eeftens $\mathrm{M}$, Beelen R, Fischer $\mathrm{P}$, et al. Stability of measured and modelled spatial contrasts in $\mathrm{NO}_{2}$ over time. Occup Environ Med 2011; 68: 765-770.

32 Gulliver J, de Hoogh $\mathrm{K}$, Hansell A, et al. Development and back-extrapolation of $\mathrm{NO}_{2}$ land use regression models for historic exposure assessment in Great Britain. Environ Sci Technol 2013; 47: 7804-7811.

33 Gulliver J, Morris C, Lee K, et al. Land use regression modeling to estimate historic (1962-1991) concentrations of black smoke and sulfur dioxide for Great Britain. Environ Sci Technol 2011; 45: 3526-3532.

34 Beijk R, Mooibroek D, Hoogerbrugge R. Air Quality in the Netherlands 2007. Bilthoven, National Institute for Public Health and the Environment, 2008.

35 European Environment Agency. Netherlands - Air Pollution Country Fact Sheet 2019. www.eea.europa.eu/ themes/air/country-fact-sheets/2019-country-fact-sheets/netherlands Date last accessed: January 23, 2020. 